Journal of Patient-Centered

$1-19-2021$

\title{
Assessment of Stakeholder Engagement in a Down Syndrome Research Study
}

\author{
Jeanhee Chung \\ Ashwini Sarathy \\ Yichuan Grace Hsieh \\ Greg Estey \\ Amy Torres \\ Vasiliki Patsiogiannis \\ Karen Donelan \\ Brian G. Skotko
}

Follow this and additional works at: https://aah.org/jpcrr

Part of the Family Medicine Commons, Health Services Research Commons, Mental and Social Health Commons, Mental Disorders Commons, Pediatrics Commons, and the Primary Care Commons

\section{Recommended Citation}

Chung J, Sarathy A, Hsieh YG, Estey G, Torres A, Patsiogiannis V, Donelan K, Skotko BG. Assessment of stakeholder engagement in a Down syndrome research study. J Patient Cent Res Rev. 2021;8:64-7. doi: 10.17294/2330-0698.1777

Published quarterly by Midwest-based health system Advocate Aurora Health and indexed in PubMed Central, the Journal of Patient-Centered Research and Reviews (JPCRR) is an open access, peer-reviewed medical journal focused on disseminating scholarly works devoted to improving patient-centered care practices, health outcomes, and the patient experience. 


\title{
Assessment of Stakeholder Engagement in a Down Syndrome Research Study
}

\author{
Jeanhee Chung, MD, ${ }^{1,2}$ Ashwini Sarathy, ${ }^{3}$ Yichuan Grace Hsieh, PhD, RN, ${ }^{1,2}$ Greg Estey PhD, ${ }^{1}$ Amy \\ Torres, BS, ${ }^{3}$ Vasiliki Patsiogiannis, BA, ${ }^{3}$ Karen Donelan, ScD, EdM, ${ }^{2,4}$ Brian G. Skotko, MD, MPP ${ }^{3,5}$ \\ ${ }^{1}$ Laboratory of Computer Science, Massachusetts General Hospital, Boston, MA; ${ }^{2}$ Department of Medicine, \\ Harvard Medical School, Boston, MA; ${ }^{3}$ Down Syndrome Program, Division of Medical Genetics and Metabolism, \\ Massachusetts General Hospital, Boston, MA; ${ }^{4}$ Health Policy Research Center, Mongan Institute, Massachusetts \\ General Hospital, Boston, MA; ${ }^{5}$ Department of Pediatrics, Harvard Medical School, Boston, MA
}

\begin{abstract}
There is growing recognition of the importance of engaging patients early in the design of research studies. For studies involving patients with intellectual and cognitive disabilities, researchers may consider engaging with family caregivers, health professionals, community advocates, and/or subject matter experts to provide a more multifaceted, surrogate perspective. Evaluating the engagement of these stakeholder groups in research is nascent, and tools are limited. Research studies involving these individuals provide the opportunity to test new methods of measurement of stakeholder engagement in research. We conducted a 3-year research study implementing and evaluating Down Syndrome Clinic to You, an online platform for caregivers of individuals with Down syndrome who do not have access to Down syndrome specialists. We established 3 key stakeholder groups - family caregivers, primary care physicians, and medical/scientific experts in the field - who were involved from grantwriting through preparation of the final report. To assess stakeholder engagement, we utilized the Patient Engagement in Research Scale, a validated instrument originally developed to evaluate patient engagement in arthritis research. Overall, results were suggestive of strong engagement levels by the key stakeholder groups. This study contributes to the limited available literature evaluating measures of stakeholder engagement in research. (J Patient Cent Res Rev. 2021;8:64-67.)
\end{abstract}

Keywords stakeholder engagement; Patient Engagement in Research Scale; PEIRS; participatory research; Down syndrome; cognitive disability

$\mathrm{P}$ atients who participate in hands-on, decisionmaking, and advisory activities at any stage of the research process - outside of their roles as study participants - are helping to fill an important gap in clinical research. By bringing their lived experiences while research teams craft study procedures and dissemination plans, patients have the potential to enrich the relevance, practical feasibility, and, ultimately, impact of the research being conducted. ${ }^{1-3}$ For patients who are children, or who have an intellectual or cognitive disability that may prevent their full participation as advisors, adopting a more holistic viewpoint on who may participate on their behalf may be considered. The inclusion of family caregivers, health professionals, community advocates, and/or subject matter experts all

Corresponding author: Jeanhee Chung, MD, MGH Laboratory of Computer Science, 50 Staniford Street, Suite 750, Boston, MA 02114 (jachung@mgh.harvard.edu) can provide important feedback on what is important to patients who are less able to communicate their needs, values, and preferences. ${ }^{3}$

Our research team recently conducted a national randomized controlled trial of an online health care platform for caregivers of individuals with Down syndrome, a genetic condition oftentimes accompanied by complex co-occurring medical conditions. ${ }^{4}$ With this platform, called Down Syndrome Clinic to You (DSC2U), family caregivers complete a comprehensive, online intake form and then receive an automatically generated checklist of personalized recommendations with a companion plan to share with the primary care provider. DSC2U was found to be effective in improving adherence to the national Down syndrome health care guidelines. ${ }^{4}$ As patients with Down syndrome all have mild to severe intellectual disabilities, the DSC2U intervention was developed for use by their concerned caregivers. We relied on these advocates to best inform our research on DSC2U, engaging key stakeholder groups (family caregivers, primary care physicians, and 
subject matter experts) over a 3-year period in the design, conduct, implementation, and dissemination of that randomized controlled trial.

However, a nominal inclusion of these patient representatives does not necessarily translate into meaningful engagement. At the conclusion of the trial, we wanted to evaluate, in some objective way, whether the engagement of those key stakeholders was truly meaningful. The development of methods to measure stakeholder engagement in research is at an early stage. Studies targeting specific patient-centered outcomes developed in partnership with patients or their caregiver representatives, such as ours, can be testbeds for the application of new methods of measurement of stakeholder engagement in research.

In this paper, we evaluate stakeholder engagement using the Patient Engagement in Research Scale (PEIRS), a validated instrument originally developed to evaluate patient stakeholder engagement in arthritis research. ${ }^{1} \mathrm{We}$ sought to extend this body of literature to a novel set of patient representatives.

\section{METHODS}

\section{Description of Stakeholder Involvement}

We established 3 working groups to support our study. The Caregiver Working Group consisted of 7 individuals from across the United States - mothers who had sons or daughters with Down syndrome and/or leaders of Down syndrome nonprofit organizations. The Primary Care Physician Working Group consisted of 4 physicians located in Massachusetts, Oregon, and New Hampshire, each with 1 to 5 patients with Down syndrome in their practices. The Expert Working Group consisted of 5 physicians and scientists with expertise in developmental pediatrics, mental health wellness in teens and adults, informed medical decision-making, genetics, and internal medicine.

Each stakeholder group met separately for an hour every month by teleconference, led by representatives from the core research team, including the principal investigator (PI) and research assistant. Other core research team members attended periodically to discuss key documents such as consent information, survey questions, website copy, or clinical algorithms. These discussion-format meetings began from the inception of grant writing in August 2015 and continued through the completion of the study in August 2019. Before these meetings, working group members received a detailed agenda, distributed by Google Docs, which provided access to real-time sharing. Following each meeting, the research assistant sent out detailed meeting notes via the same mechanism.
Working group members were engaged with every phase of the study and offered feedback on all aspects of the DSC2U intervention, including design of the informational project website, the content of the online intake, and the algorithms behind the customizable content that would be shared with caregivers and primary care providers. Stakeholders also refined study outcomes, brainstormed recruitment strategies, and reviewed interim and final data analyses. Toward the end of the trial, working groups also were particularly instructive in strategies to disseminate the findings within the Down syndrome community.

\section{Participants}

All members of the 3 working groups were invited to participate in the PEIRS survey evaluation. To provide a benchmark, the core research team comprising 8 researchers from Massachusetts General Hospital (Boston, MA) who were primarily responsible for the creation of DSC2U also were surveyed. This team included physicians, software engineers, statisticians, survey methodologists, and research assistants.

\section{Survey Instrument}

PEIRS is a framework designed by Hamilton et al at the University of British Columbia (Vancouver, Canada). ${ }^{1}$

It was developed, with content and face validation, to quantifiably assess meaningful patient engagement throughout the research process from the patient perspective. The PEIRS survey includes 37 questions, each using a 5-point Likert rating scale, organized across 7 conceptual themes: procedural requirements, convenience, contributions, team environment, support, research environment, feeling valued, and benefits. ${ }^{1}$

For this study, the PEIRS survey was used in its entirety, with only slight wording changes to address questions to our 3 working group members instead of patients. The core research team (described in detail under "Participants") reviewed the PEIRS and felt that face validity was appropriate for our purposes. To give our participants the opportunity to share feedback that may not have been covered by the PEIRS, our questionnaire concluded with 2 additional open-ended questions:

- "Thinking about your experience working on the DSC2U project, what do you believe were its most important areas of strength?"

- "Thinking about your experience working on the DSC2U project, what were areas that could have used some improvement?"

The original PEIRS was self-administered on paper at a stakeholder meeting; we administered our questionnaire electronically at the conclusion of the 3-year study 
period using REDCap (Research Electronic Data Capture) electronic data capture tools hosted at Partners HealthCare (Boston, MA). ${ }^{5,6}$ REDCap is a secure, web-based software platform designed to support data capture for research studies. All 23 members across the 4 groups received an initial invitation by email and up to 3 reminders by email. Responses were anonymous.

\section{Analysis}

The PEIRS scoring guide was used to calculate the total score. ${ }^{1}$ Each item was first converted from its 5-point Likert scale descriptive category (strongly agree to strongly disagree) to a numerical score. The sum of scores across all 7 themes was calculated for each respondent, then divided by the total maximum score of 148 and multiplied by 100 to calculate a PEIRS total score.

\section{RESULTS}

Of the 23 persons invited to participate during the period from June to July 2019, 22 (95.7\%) completed the survey across the 3 categories of stakeholders (ie, caregivers, primary care physicians, and expert advisors) and the core research team members. The average total score on the PEIRS instrument was 93.5 out of a maximum of 100 (Table 1). Experts ranked their experience in the DSC2U research process the most favorably (PEIRS total score: 97.8); primary care physicians had the lowest score (PEIRS total score: 86.7).

Respondents identified project strengths in verbatim response questions, which included the effective leadership of the PI: "[He] brought a great team of researchers and parents together to create a tool that is useful and beneficial to the community." and "The objective behind it was such a good one, it was hard not to be excited to be a part of it. The meetings were well organized and efficient and [the PI] is so incredibly positive that it is contagious."

Table 1. Mean PEIRS Total Scores by Stakeholder Group, Overall

\begin{tabular}{lcc}
\hline Stakeholder group & $\mathbf{n}$ & $\begin{array}{c}\text { Mean PEIRS } \\
\text { total score }\end{array}$ \\
\hline Core research team & 8 & 94.9 \\
Expert advisors & 3 & 97.8 \\
Caregivers & 7 & 94.6 \\
Primary care physicians & 4 & 86.7 \\
- \hdashline Overall & 22 & 93.5 \\
\hline
\end{tabular}

PEIRS, Patient Engagement in Research Scale.
Respondents also commented about the organization of the project: "The project was a very collaborative process. Attention to detail also a strength." and "Clear, concise communication. Strong respectful team with dedication to the project and purpose."

Respondents were asked to identify areas for improvement. A few stakeholders in the external groups noted that it might have been productive to have meetings clustered around the needs of the project rather than at predetermined intervals. Given the amount of work in the initial phases, some stakeholders suggested that having more frequent meetings early in the project would have been beneficial. Others commented that there could have been less frequent meetings once the study was underway, especially during the randomized controlled trial period when the project was running smoothly.

\section{DISCUSSION}

The PEIRS total scores varied slightly among the 4 groups of respondents but were all suggestive of strong engagement levels by key stakeholders. However, the PEIRS survey does not yet offer a way of understanding how to interpret these total scores and subgroup differences. That primary care physicians scored lower than the other groups has some face validity, as Down syndrome care and research influences their professional and personal lives the least, particularly when compared to families of a loved one with Down syndrome or community advocates and research experts who have built their professions around Down syndrome.

There is growing literature advocating for greater engagement of patients and caregivers in research as well as expanding efforts by sponsors to ensure stakeholder engagement. ${ }^{\text {cf.7 }}$ Even among individuals with intellectual disability, ${ }^{8}$ including those with Down syndrome, ${ }^{9}$ researchers are thinking of creative ways to engage these groups at different stages in the research process to mutual benefit. A recently published report on stakeholder experience also noted the unexpected therapeutic benefit of engaging in patient-centered research. ${ }^{10}$ There are, however, few studies that evaluate any measures of engagement, one of the first steps in understanding its value and building an evidence base for its practice ${ }^{\text {cf. } 11}$ Given the current climate of encouraging patient and stakeholder participation in publicly funded research, we were surprised to find relatively few reports of stakeholder experience in the literature.

We did not re-validate the PEIRS for our mixedstakeholder participant group; if we had done so, this group of stakeholders might have identified additional important measures to include. Also, administering this 
survey at the conclusion of the study period rather than at regularly scheduled intervals made it impossible to act on recommended changes and thwarted any opportunity to see if and how engagement might have evolved. Nevertheless, the survey proved a useful way to engage stakeholders in a final step of assessing our research process and outcomes.

In summary, this study demonstrated that an assessment of stakeholder involvement in research for people with intellectual disabilities is possible and warranted.

\section{Patient-Friendly Recap}

- Contemporary research standards push for obtaining patient input on study design and execution. However, this may be unrealistic when the targeted population has an intellectual disability.

- In a randomized controlled trial for patients with Down syndrome, authors collaborated with various surrogates (family caregivers, primary physicians, Down syndrome experts) in lieu of patient engagement.

- After the trial's conclusion, participating stakeholders were surveyed regarding their involvement in the research project.

- High scores of engagement were reported by all stakeholder groups, suggesting this type of patientoriented research may be achievable when direct patient involvement is not.

\section{Acknowledgments}

Our research team would like to give a special thanks to Clayon B. Hamilton and the PEIRS development team of the University of British Columbia for their generous permission to use the PEIRS survey tool for this study.

\section{Author Contributions}

Study design: Chung, Estey, Donelan. Data acquisition or analysis: Chung, Sarathy, Hsieh, Torres, Patsiogiannis, Donelan. Manuscript drafting: Chung, Sarathy, Estey, Donelan, Skotko. Critical revision: Hsieh, Estey, Patsiogiannis, Donelan, Skotko.

\section{Conflicts of Interest}

Dr. Skotko occasionally consults on the topic of Down syndrome through Gerson Lehrman Group. He receives remuneration from Down syndrome nonprofit organizations for speaking engagements and associated travel expenses. Dr. Skotko receives annual royalties from Woodbine House, Inc., for the publication of his book, Fasten Your Seatbelt: A Crash Course on Down Syndrome for Brothers and Sisters. Within the past 2 years, he has received research funding from F. Hoffmann-La Roche, Inc., and LuMind Research Down Syndrome Foundation to conduct clinical trials for people with Down syndrome. Dr. Skotko is occasionally asked to serve as an expert witness for legal cases where Down syndrome is discussed. He serves in a nonpaid capacity on the Honorary Board of Directors for the Massachusetts Down Syndrome Congress and the Professional Advisory Committee for the National Center for Prenatal and Postnatal Down Syndrome Resources. Dr. Skotko has a sister with Down syndrome.

\section{Funding Sources}

Study funding was received from the Patient-Centered Outcomes Research Institute (AD-1507-31567).

\section{References}

1. Hamilton CB, Hoens AM, McQuitty S, et al. Development and pre-testing of the Patient Engagement In Research Scale (PEIRS) to assess the quality of engagement from a patient perspective. PLoS One. 2018;13(11):e0206588. CrossRef

2. Frank L, Forsythe L, Ellis L, et al. Conceptual and practical foundations of patient engagement in research at the patient-centered outcomes research institute. Qual Life Res. 2015;24:1033-41. CrossRef

3. Sprague Martinez L, Carolan K, O'Donnell A, Diaz Y, Freeman ER. Community engagement in patient-centered outcomes research: benefits, barriers, and measurement. J Clin Transl Sci. 2018;2:371-6. CrossRef

4. Chung J, Donelan K, Macklin EA, et al. A randomized controlled trial of an online health tool about Down syndrome. Genet Med. 2021;23:163-73. CrossRef

5. Harris PA, Taylor R, Thielke R, Payne J, Gonzalez N, Conde JG. Research electronic data capture (REDCap) - a metadatadriven methodology and workflow process for providing translational research informatics support. J Biomed Inform. 2009;42:377-81. CrossRef

6. Harris PA, Taylor R, Minor BL, et al. The REDCap consortium: building an international community of software platform partners. J Biomed Inform. 2019;95:103208. CrossRef

7. Macaulay AC. Participatory research: What is the history? Has the purpose changed? Fam Pract. 2017;34:256-8. CrossRef

8. O'Brien P, McConkey R, García-Iriarte E. Co-researching with people who have intellectual disabilities: insights from a national survey. J Appl Res Intellect Disabil. 2014;27:65-75. CrossRef

9. Stevenson M. Participatory data analysis alongside coresearchers who have Down syndrome. J Appl Res Intellect Disabil. 2014;27:23-33. CrossRef

10. Sheehan OC, Ritchie CS, Garrett SB, et al. Unanticipated therapeutic value of the Patient-Centered Outcomes Research Institute (PCORI) stakeholder engagement project for homebound older adults. J Am Med Dir Assoc. 2020;21:1172-2. CrossRef

11. Dillon EC, Tuzzio L, Madrid S, Olden H, Greenlee RT. Measuring the impact of patient-engaged research: how a methods workshop identified Critical Outcomes of Research Engagement. J Patient Cent Res Rev. 2017;4:237-46. CrossRef

(C) 2021 Advocate Aurora Health, Inc. 